\title{
Fluorine F 18 L-glutamate Derivative BAY94-9392
}

National Cancer Institute

\section{Source}

National Cancer Institute. Fluorine F18 L-glutamate Derivative BAY94-9392. NCI

Thesaurus. Code C116735.

A radioconjug ate composed of the radionuclide fluorine $\mathrm{F} 18$ conjug ated to the Lglutamate derivative, (S)-4-(3-fluoropropyl)-L-glutamic acid (FSPG), targeting the cystine/g lutamate transporter protein (XCT or SLC7A11), which is a subunit of the transport system $\times c(-)$, with potential imaging activity upon positron emission tomography (PET). Upon intravenous administration, the FSPG moiety of BAY94-9392 specifically binds to XCT and BAY94-9392 is subsequently taken up by the cell via xc(-). Upon uptake, xc(-) activity can be assessed and tumor cells can be detected and imaged by PET. System xc(-), a sodium-independent, heterodimeric transporter, mediates the cellular uptake of cystine in exchange for intracellular glutamate at the plasma membrane; although, it will take up glutamate as well. Xc(-) shows increased activity in certain tumor cells compared to normal, healthy cells due to increased metabolic activity in tumor cells; it plays a key role in tumor cell proliferation, progression and chemoresistance as well as in the management of oxidative stress. 